\title{
Macroeconomic Factors Influencing Public Policy Strategies for Blue and Green Hydrogen
}

\author{
Roberto Fazioli * and Francesca Pantaleone \\ Department of Economics, University of Ferrara, 44121 Ferrara, Italy; Francesca.pantaleone@edu.unife.it \\ * Correspondence: fzlrrt@unife.it; Tel.: +39-3-496-501-787
}

\begin{abstract}
The aim of this paper is to analyze the factors affecting hydrogen and Carbon Capture and Storage Technologies ("CCS") policies, taking into consideration Fossil Fuel Consumption, Oil Reserves, the Debt/GDP Ratio, the Trilemma Index and other variables with respect to OECD countries. STATA 17 was used for the analysis. The results confirm the hypothesis that countries with high fossil fuel consumption and oil reserves are investing in blue hydrogen and CCS towards a "zero-carbon-emission" perspective. Moreover, countries with a good Debt/GDP ratio act most favorably to green policies by raising their Public Debt, because Foreign Direct Investments are negatively correlated with those kinds of policies. Future research should exploit Green Finance policy decision criteria on green and blue hydrogen.
\end{abstract}

Keywords: blue hydrogen; green hydrogen; carbon capture; sustainability; energy transition

check for

updates

Citation: Fazioli, R.; Pantaleone, F. Macroeconomic Factors Influencing Public Policy Strategies for Blue and Green Hydrogen. Energies 2021, 14, 7938. https://doi.org/10.3390/ en14237938

Academic Editor: Federica Raganati

Received: 25 October 2021

Accepted: 22 November 2021

Published: 26 November 2021

Publisher's Note: MDPI stays neutral with regard to jurisdictional claims in published maps and institutional affiliations.

Copyright: (c) 2021 by the authors. Licensee MDPI, Basel, Switzerland. This article is an open access article distributed under the terms and conditions of the Creative Commons Attribution (CC BY) license (https:// creativecommons.org/licenses/by/ $4.0 /)$.

\section{Introduction}

The aim of this paper is to analyze the factors influencing blue and green hydrogen investments in Europe. The growing international concerns of climate change and oil import dependence are not a surprise, such that a greater interest in hydrogen energy has come as a consequence [1]. Today, several factors have led to growing interest in a hydrogen energy economy, especially for transportation and the need to store renewable electricity supplies [2]. However, very few empirical works have been developed to address the crucial question of "how" to spread the use of hydrogen, or "how to get it". Today, in fact, the academic and political debate has already assumed the need for the use of hydrogen, but still unclear and unambiguous are the positions regarding the types of hydrogen production process that must be perpetuated and implemented for the so called "sustainable energy transition" [3]. Policy plays a key role in the promotion of different paths of energy sources exploitation, and much research has been conducted to assess its effects on renewable energy innovation $[3,4]$.

In order to contribute to such a debate, our work has been set on the analysis of public policy factors that can play a significant role in the orientation of policies towards the affirmation of hydrogen economies.

This paper is structured as follows: the introduction will cover an overview of the current political and economic framework, trying to emphasize the importance of investing in hydrogen and its related costs. The empirical analysis will then focus on the investigation of which factors better and mostly impact hydrogen investment decisions. The idea is to understand which countries are currently investing in hydrogen, and whether they are more focused on blue or green hydrogen. The results will show that some factors affect blue hydrogen and the correlated carbon capture technologies, such as the amount of oil reserves and the dependance on fossil fuels of a country, and most importantly that financing constraints might play a crucial role in investment decisions. 


\subsection{Investing in Hydrogen}

The strategic repositioning of "national" energy policies has resumed the progressive affirmation of an increasingly wide collection of consensuses on the issues of sustainability [5], which has also used the renewed the need for energy policies of independence and autonomy. This happened in particular ways in countries which had and are currently having difficulties in importing hydrocarbons from countries of verified complexity, variability, and direct and indirect burdens [6].

The search for an increasingly sustainable national energy mix needs to be viewed in accordance with the search for national or local autonomy in the generation of green energies, which are becoming more and more essential to the economic development of each nation [7]. National policies have followed this lead by focusing on sustainable energies, both directly and indirectly financed from governments [8]. CCS and hydrogen are becoming the main characters of a new Sustainable Development Scenario all over the world. Policymakers and experts argue about whether to invest in green or blue hydrogen, but the different point of views seem to converge into finding massive public support to enhance the efficient hydrogen supply chain. The European Commission's strategy "A hydrogen strategy for a climate-neutral Europe" [9] is already addressing the ways in which to exploit hydrogen investments, and finding the necessary instruments. On the one side, there is "green" hydrogen with low carbon emissions, and on the other there is the intent of developing infrastructures for hydrogen transport and storage.

The New Green Deal plays a crucial role in improving energy efficiency, energy autonomy and reaching sustainability goals: hydrogen strategies have been implemented inside the New Green Deal. The strategy adopted by the European Commission foresees three phases-2020-2025, 2025-2030, and 2030-2050-which assume objectives such as [9]:

- $\quad$ Reducing hydrogen costs of production from industrial processes with low Greenhouse Gases ("GHG") emissions.

- Exploiting all possible synergies with existing and feasible infrastructures for the logistical diffusion of the potential of hydrogen.

- Reducing the cost of generating renewable electricity, including the reduction of the hydrogen costs of production due to industrial processes with low GHG emissions.

- Reductions in the capital expenditures of the electrolysers, in particular the large ones: from about $900 € / \mathrm{kW}$ today to $450 € / \mathrm{kW}$ in 2030 (this forecast is slightly more optimistic than that of the aforementioned IEA ratio, which indicates $550 € / \mathrm{kW}$ ) and down to $180 € / \mathrm{kW}$ after 2040.

- Exploiting all of the possible synergies with existing and feasible infrastructures for the logistical diffusion of the potential of hydrogen. This includes maximizing the value of the innovations introduced by the use of hydrogen in the verticalization of industrial processes.

- In the long term (after 2040), green hydrogen should reach full maturity and become competitive; in the meantime, space and incentive should be given to blue hydrogen with CCS.

- Blue hydrogen investments should progressively increase through subsides, pilot projects, and EU and national funds, in order to boost both demand and offers.

- We are close to a turning point with respect to the goals mentioned above. Between November 2019 and March 2020, market analysts increased the list of planned global investments in electrolysers from 3.2 GW to $8.2 \mathrm{GW}$ by 2030 (of which $57 \%$ will be in Europe) [10].

The number of companies that have joined the International Hydrogen Council grew from 13 in 2017 to 81 as of today. The Council aims to promote the meaningful use of hydrogen in various strategic fields, and to identify the current limits that must be solved thanks to the governments' support [11]. 


\subsection{Hydrogen and CCS}

Hydrogen is the new resource which is seen as a new achievable sustainable perspective for green energy mix policies. It can both be used as energy carrier and an energy source. Hydrogen has been labeled according to its original energy source:

- "Grey" hydrogen, from natural gas to hydrogen.

- "Brown" hydrogen, from coal to hydrogen.

- "Blue" hydrogen, from natural gas to hydrogen with the storage of $\mathrm{CO}_{2}$.

- "Green" hydrogen: from water, via electrolysis, to hydrogen. This is the only method which is usually considered to be a " $100 \%$ Green" solution to create clean power energy.

- "Purple" hydrogen, from electrolysis supported by nuclear energy.

However, there is another potential way to view hydrogen: as energy storage. Batteries may be a cheaper means of storing energy in the short-term, but hydrogen can be stored indefinitely, offering a potential solution to the current challenges weighing on the energy industry.

Green hydrogen is more and more often considered to be a "game changer" in some sort of "fight against climate change", because it usually enables the decarbonization of difficult-to-decarbonize sectors. Green hydrogen can convert wind and solar energy to a flexible zero-carbon fuel that can displace many fossil fuel applications. The demand for this hydrogen already exists, with some 100 million metric tons of hydrogen already in use in industrial applications. Most of today's hydrogen is produced by using steam methane reforming or other methods to extract hydrogen from fossil fuels. Green energy could decarbonize this existing industry by the use of curtailed wind and solar energy to split water into hydrogen and oxygen by way of electrolysis.

According to the European Commission's July Hydrogen Strategy [8], the actual indicative costs for hydrogen production today are:

- $\quad 38 € / M W h$ for current high-carbon production;

- $\quad 50 € / M W h$ for "blue" hydrogen with CCS;

- $\quad 65-135 € /$ MWh for "green" hydrogen.

It is important to remark that these costs-especially those related to blue hydrogen -are merely indicative, because they are very location specific. Moreover, because there are some difficulties in finding the right metal hydrides to match with the necessary criteria, the possibility of a storage system of hydrogen is still uncertain [12].

It is also important to consider the costs of developing an efficient infrastructure system: according to Enagàs, Snam and other companies [13], the investment costs of a complete infrastructure development-not including storage, distribution pipelines and $\mathrm{CO}_{2}$ infrastructures-vary from 27 to 64 billion euro, covering full capital costs of the project, while OPEX costs might range from 106 to 3.5 billion euro. Most of the average total costs for these projects are still under evaluation, but it is a common fact that hydrogen and CCS plants are very expensive-especially in capital and operating costs-and unfortunately, they do not seem to provide a clear net margin in the short-term due to their high production costs, as mentioned before in this paper. The European Hydrogen Alliance [9] was born to sustain a financing solution: governments should support local/national private entities to enhance investments in both blue and green hydrogen. It is also worthwhile to mention the importance of the cost reduction potential in the long term for those policies.

Carbon capture also plays a crucial role in energy transition, even if it remains an area of debate. According to the "Global Status of CCS" Report [14], CCS facilities can be summarized into:

- Large-scale CCS facilities, which are able to capture large capacities of $\mathrm{CO}_{2}$ from industrial sources and power generation, including transport and storage hubs projects, of around 400-800 ktpa. Those facilities must be covered by commercial return in both the capture and storage phases. 
- Small-scale CCS facilities, which are able to capture $\mathrm{CO}_{2}$ from power or industrial sources under the abovementioned thresholds. These facilities are more for the testing of strategies, and they do not expect a commercial return on those projects.

Current CCS facilities are able to capture $40 \mathrm{Mt}$ of $\mathrm{CO}_{2}$ per year. As the decarbonization of one ton of steel requires 627 cubic meters of green hydrogen, in a steel plant with an annual production of 4 million tons of steel the electricity required by a polymer electrolyser to make available all of the hydrogen needed would be about $8800 \mathrm{GWh}$. To power it, all of the electricity $(8400 \mathrm{GWh})$ generated by the large offshore park of $2.8 \mathrm{GW}$, planned in the Channel of Sicily, would not be enough. Assuming that, in 2030, the efficiency of the electrolysers is a little higher than expected today, linked to wind energy sources, it would be possible to decarbonize half of the 8 million tons of steel which, according to the Federmanager study, should still be produced in blast furnaces. Moreover, the use of photovoltaic plants would require the total employment of 6000-7000 hectares: this objective seems unrealistic, because this technology will have to provide the most important share of the energy required to achieve the other objectives of the new PNIEC, revised upwards.

Chapman et al. [14] have shown that hydrogen can be efficiently used for the transport sector, reducing $30 \%$ of $\mathrm{CO}_{2}$ emissions. By observing the latest CCS plants, it is easy to notice an evident cost reduction with respect to their predecessors: new plants can benefit from technology spillovers-increased learning-by-doing-and scale economies. Adding more projects will trigger commercial and industrial synergies through the exploitation of supply chains and the reduction of the unit cost of $\mathrm{CO}_{2}$ storage. Hydrogen can be transported through re-converted natural gas pipelines: because it is less dense than natural gas, the energy capacity transport needs to be converted to adjust the right volumes of hydrogen [15]. However, the implementation of the whole system, from production and hydrogen development to inter-seasonal storage, for the transport system requires huge CAPEX investments, including the ones necessary for carbon capture.

Having stated that countries need to find new technologies and invest in eco-innovation to meet the expectations held by the New Green Deal and Paris Agreement, understanding which factors do affect investment policies in hydrogen is not as straightforward as projected.

There are currently seven projects regarding the generation of hydrogen from fossil fuels with CCUS, which lead to an annual production of $0.4 \mathrm{MtH}_{2}$ and $\mathrm{CO}_{2}$ capture close to $6 \mathrm{MtCO}_{2}$. This dualism also facilitates the reduction of the costs related to the creation of a $\mathrm{CO}_{2}$ capture plant—which often becomes unsustainable on its own —or a completely green system based on water electrolysis. By reducing the price of electricity, it is possible to reduce the cost of hydrogen production; another possibility is to split the design of a steam methane reformer from the $\mathrm{CO}_{2}$ capture and compression plant, in order to optimize the cost-saving of the overall process. New $\mathrm{CO}_{2}$ plants are indeed focused on minimizing the steam extraction inefficiencies and recovering waste heat from the plant steam cycle. Moreover, it is important to underline that hydrogen produced from gas or coal is obtained with fewer electricity sources compared to green ones. As the CCS institute [13] reports, a production of $1.76 \mathrm{Mt}$ of hydrogen from steam methane reformation with CCS implies four $\mathrm{CO}_{2}$ injections over a $2 \mathrm{~km}^{2}$ plant. In particular, Europe can benefit from blue hydrogen-CCS production due to its large industrial clusters, pipelines and geological storage potential.

According to the IEA [16], in the long-run $40 \%$ of the global hydrogen produced will be blue, and $18 \%$ of this production will be captured by attached CCS plants. As a consequence, countries with high fossil fuel consumption and oil reserves might decide to invest in these policies to mitigate their emissions levels.

The literature is wide on the technical aspects of hydrogen as a new source of energy, but the analysis of macroeconomic factors seems to be more trivial.

A broadened piece of research from Noailly and Smeets [17] considering renewable energies in general terms showed that firms specializing in renewable technologies are more 
vulnerable to financing constraints than firms investing in fossil fuels. This result holds for small and large firms as well. This might mean that investing in renewables is riskier than investing in fossil fuel. This is also confirmed by Safarzyńska et al. [18], who outlined the way in which price stability might mine investments in renewable energies, especially in coal-dependent economies.

Wietschel et al. [19] addressed the question from several points of view, including input-output, a general equilibrium model, system dynamics and econometric analysis. They concluded that hydrogen as an energy carrier might be linked with GDP, welfare and employment at both the national and regional level; in particular, competitiveness might be the trigger to incentivize hydrogen investments.

Tseng et al. [20] used a Market-Allocation ("MARKAL") model to estimate the impacts on hydrogen in the US economic energy system, discovering that, overall, a hydrogen economy might boost energy efficiency by lowering the consumption of oil and derivatives. They also addressed the fact that, in order to fight the most impeding cost-barrier of hydrogen production, coal seems to be the most competitive way to produce it, without considering its consequences on emissions. They also stressed the importance of capturing the $\mathrm{CO}_{2}$ deriving from gray/blue hydrogen production, even though it might add $25 \%$ or $30 \%$ to the overall costs of hydrogen production [21]. Nevertheless, there seems to be a trend in the cost-reduction of hydrogen production which leads to a massive reduction in the spread of investment costs [22]. Some of the reasons might rely on improved supply chains and higher-volume production, along with technology innovation.

A similar approach has been used by Kawakami et al. [23], who analyzed the impact of $\mathrm{CO}_{2}$ targets on Japan's energy system towards 2050. In their research, among other factors, they considered GDP, fossil fuel and hydrogen import spending, the average energy price and energy supply, the carbon price and the amount of hydrogen introduced. Their research shows that emission reduction targets might not be enough to push countries towards energy transition, due to greater economic pressure.

Lee [24] forecast the economic consequences of hydrogen on South Korea's energy system through a general equilibrium model, stating that hydrogen development might lead to the reduction of the production cost and GDP growth in the end. Most importantly, he concluded that hydrogen energy needs to come from non-fossil fuel sources in order to effectively reduce greenhouse gases emissions, in which government intervention plays a crucial role.

Stavytskyy et al. [25], in their research, showed that increasing production from renewable sources leads to a better energy security efficiency, which might trigger energy supply and investments in technologies. Moreover, they discovered-through the clustering of European countries - that energy security might affect different reactions to international changes towards the production and distribution of energy.

\section{Materials and Methods}

\subsection{Rationale}

Following the abovementioned examples from the literature, this paper aims to address the research gap of the understanding of macroeconomic outcomes on hydrogen from a different point of view and with respect to current policies. The paper will focus on financing constraints in order to confirm their relevance in the relationship between green policy intensity and variables that might impact policymakers' decisions. In particular, we do expect similar patterns between green and blue hydrogen investment decisions, even though choosing the first or second technology might rely on the nature of the country and its dependance on fossil fuel consumption. Indeed, we observe the ongoing efforts of different nations to use hydrogen to reduce their dependence on petroleum imports. About 9 million tons of hydrogen are produced each year in the US and 50 million tons worldwide, mostly and most cheaply from the steam reforming of natural gas [26]. Dunn [27] opened their introduction with the depiction of ongoing efforts by different nations to reduce their dependence on oil. According to Dunn, all of the increased interests in hydrogen 
perspectives stem from the counter measures to the issues of energy security, air pollution, and climate change. Dunn suggests that nations' renewed interests in hydrogen are mainly due not only to the advent of technological advances but also to the resolution for risk posed by the current dependence on petroleum use.

By looking at IEA's [16] hydrogen policy database, we can observe that only 66 projects out of 222 are financed by private investments: the most important are the hydrogen refueling station in Netherlands, the NCG conversions to $\mathrm{H}_{2}$ in the UK, and several power supply and demand projects in Brasil. Yara and Evoenergy are financing a renewable ammonia plant and hydrogen test facility in Australia, and there are some ongoing investments in the transport sector from automotive industry companies. Most of the projects are financed by public funds or public-private partnerships. The range of funding amounts (national currency 2018) might be very wide, like the 250 million euro "National Innovation Programme Hydrogen and Fuel Cell Technology" project financed by the German Ministry of Transport and digital infrastructure. According to the EEA Report [10] on sustainability transition in Europe, there are some remarkable fiscal sustainability risks for Belgium, Spain, Italy, Luxembourg, and Hungary in the medium and long term; matching with our hypothesis, evidence of hydrogen and CCUS projects in those countries is lacking. In the US, some CCS projects will benefit from the California low-carbon fuel standard (LCFS) and 2018's tax credit law [28].

For the reasons explained above, we expect to see a relationship between $\mathrm{H}_{2}-\mathrm{CCS}$ policies and the Government's Public Debt, which is necessary to sustain those initiatives. Following Nicolli and Vona's [29] approach to heterogeneous policies and technologies, we considered blue and green policies based on IEA's [16] Hydrogen Policies Database and IOGP's (2020) Global CCUS projects. We constructed a dummy variable equal to one which corresponds to countries currently carrying out hydrogen policies, and an analogous dummy for CCUS policies. We considered both current active and announced initiatives which have not yet started. This is because most of the observed policies started in 2020, but most of their costs were already included in 2019's budgets. This is the main reason why we decided to consider a cross-sectional dataset taking into consideration 2019 as the base year. Another reason is because we wanted to avoid some biases on macroeconomic indices due to the COVID-19 pandemic for the year 2020. Then, we will take into consideration Foreign Direct Investments and other variables indirectly related to green policy measures.

In order to better address the scenario considering different hydrogen categories, we also constructed a categorical variable that assumes a value of 0 for CCUS policy types, a value of 1 for countries which currently have both CCUS and hydrogen policies in place, a value of 2 for hydrogen policies, and a value of 4 for none of the above.

\subsection{Data Analysis}

Most of the data were retrieved from the GlobalEconomy dataset, while the Fossil Fuel Consumption data of 2019 were retrieved from Our World in Data [30]. The data on hydrogen were taken from IEA database [16]. We took into consideration 71 countries for the 2019 period, considering the information available. A cross-sectional analysis was chosen in order to avoid spatial autocorrelation in the per capita income in relation to the other explanatory variables [31].

Table 1 in the Appendix reports a first look at the dataset considering the two dummy variables created for the paper's analysis. It shows that of 71 countries, 32 have invested in $\mathrm{CCS}$ or hydrogen policies. Of these, as many as half show a dualism of their CCS- $\mathrm{H}_{2}$ policy. In the table, the " $\mathrm{H}_{2}$ only" policies uncover green hydrogen policies currently in progress or already in place. This figure highlights some important remarks: those countries investing in CCUS and hydrogen policies for decarbonization targets are very solid innovative countries like Denmark, the Netherlands and Germany, with a very positive economic and financial situation for those countries. There are a few exceptions, such as Spain, Thailand, Argentina, and Italy; further exploiting the nature and the background of green policies 
and financing in those countries goes beyond the aim of this paper, but it is important to underline that the European Union is providing solid financial sustenance to fulfill New Green Deal strategies towards 2030.

Table 1. Countries overview for the binary dependent variable.

\begin{tabular}{|c|c|c|}
\hline Country & $\mathrm{H}_{2}$ Policy & CCUS \\
\hline Algeria & 0 & 0 \\
\hline Argentina & 1 & 0 \\
\hline Australia & 1 & 1 \\
\hline Austria & 1 & 0 \\
\hline Azerbaijan & 0 & 0 \\
\hline Bangladesh & 0 & 0 \\
\hline Belgium & 1 & 1 \\
\hline Brazil & 1 & 1 \\
\hline Bulgaria & 0 & 0 \\
\hline Canada & 1 & 1 \\
\hline Chile & 0 & 0 \\
\hline China & 1 & 1 \\
\hline Colombia & 0 & 0 \\
\hline Croatia & 0 & 1 \\
\hline Cyprus & 0 & 0 \\
\hline Denmark & 1 & 1 \\
\hline Ecuador & 0 & 0 \\
\hline Egypt & 0 & 0 \\
\hline Estonia & 0 & 0 \\
\hline Finland & 0 & 0 \\
\hline France & 1 & 1 \\
\hline Germany & 1 & 1 \\
\hline Greece & 1 & 0 \\
\hline Hungary & 0 & 0 \\
\hline Iceland & 0 & 1 \\
\hline India & 1 & 1 \\
\hline Indonesia & 0 & 1 \\
\hline Iraq & 0 & 0 \\
\hline Ireland & 1 & 0 \\
\hline Israel & 0 & 0 \\
\hline Italy & 1 & 1 \\
\hline Japan & 1 & 1 \\
\hline Kazakhstan & 0 & 0 \\
\hline Kuwait & 0 & 0 \\
\hline Latvia & 0 & 0 \\
\hline Lithuania & 0 & 0 \\
\hline Luxembourg & 0 & 0 \\
\hline Malaysia & 0 & 0 \\
\hline
\end{tabular}


Table 1. Cont.

\begin{tabular}{|c|c|c|}
\hline Country & $\mathrm{H}_{2}$ Policy & CCUS \\
\hline Mexico & 0 & 0 \\
\hline Morocco & 0 & 0 \\
\hline Netherlands & 1 & 1 \\
\hline New Zealand & 1 & 1 \\
\hline North Macedonia & 0 & 0 \\
\hline Norway & 1 & 1 \\
\hline Oman & 0 & 0 \\
\hline Pakistan & 0 & 0 \\
\hline Peru & 0 & 0 \\
\hline Philippines & 0 & 0 \\
\hline Poland & 0 & 0 \\
\hline Portugal & 0 & 0 \\
\hline Qatar & 0 & 1 \\
\hline Romania & 0 & 0 \\
\hline Russia & 0 & 0 \\
\hline Saudi Arabia & 0 & 1 \\
\hline Singapore & 0 & 0 \\
\hline Slovakia & 0 & 0 \\
\hline Slovenia & 1 & 0 \\
\hline South Africa & 0 & 1 \\
\hline Spain & 1 & 0 \\
\hline Sri Lanka & 0 & 0 \\
\hline Sweden & 1 & 0 \\
\hline Switzerland & 0 & 0 \\
\hline Thailand & 1 & 0 \\
\hline Trinidad and Tobago & 0 & 0 \\
\hline Turkey & 1 & 0 \\
\hline Ukraine & 0 & 0 \\
\hline United Arab Emirates & 0 & 1 \\
\hline United Kingdom & 1 & 1 \\
\hline USA & 1 & 1 \\
\hline Venezuela & 0 & 0 \\
\hline Vietnam & 0 & 0 \\
\hline
\end{tabular}

Table 2 shows a brief description of the variables used for the model estimation, while Table 3 reports the descriptive statistics. 
Table 2. Variable summary.

\begin{tabular}{ccc}
\hline Variable Storage & Display & Value \\
\hline Name Type & Format & Label Variable Label \\
\hline $\mathrm{H}_{2 \_ \text {policy byte }}$ & $\% 10.0 \mathrm{~g}$ & 0-no $\mathrm{H}_{2}$ policy; 1- $\mathrm{H}_{2}$ policy \\
\hline CCS byte & $\% 10.0 \mathrm{~g}$ & 0-no CCS policy; 1-CCS policy \\
\hline Policy_type long & $\% 9.0 \mathrm{~g}$ & CCS only_CCUS + $\mathrm{H}_{2}$ - Green $\mathrm{H}_{2}$ - none \\
\hline FossFuelCons double & $\% 10.0 \mathrm{~g}$ & Fossil Fuel cons, in $\mathrm{k}(2019)$ \\
\hline Tril_Index double & $\% 10.0 \mathrm{~g}$ & Tilemma Index (2019) \\
\hline Oil_reserves double & $\% 10.0 \mathrm{~g}$ & Oil reserves, billion barrels (2019) \\
\hline DebtGDPratio double & $\% 10.0 \mathrm{~g}$ & debt/GDP (2019) \\
\hline FDI double & $\% 10.0 \mathrm{~g}$ & Foreign Direct Investment, $\%$ of GDP \\
\hline InnovationIndex double & $\% 10.0 \mathrm{~g}$ & Innovation Index (2019) \\
\hline MonetaryFreedom & $\% 10.0 \mathrm{~g}$ & Monetary Freedom Index (2019) \\
\hline Governmenteff & $\% 10.0 \mathrm{~g}$ & Government effectiveness (2019)
\end{tabular}

Table 3. Descriptive statistics.

\begin{tabular}{|c|c|c|c|c|c|}
\hline Variable & Obs & Mean & Std. Dev. & Min & $\operatorname{Max}$ \\
\hline $\mathrm{H}_{2 \_ \text {policy }}$ & 71 & 0.3521127 & 0.4810284 & 0 & 1 \\
\hline CCS & 71 & 0.3239437 & 0.4713097 & 0 & 1 \\
\hline Policy_type & 71 & 3.126761 & 1.081396 & 1 & 4 \\
\hline FossFuelCons & 71 & 1457.958 & 4744.996 & 9.701 & 33512.49 \\
\hline Tril_Index & 71 & 71.91408 & 7.901199 & 47.8 & 84.3 \\
\hline Oil_reserves & 71 & 19.50056 & 55.63106 & 0 & 302.81 \\
\hline DebtGDPratio & 71 & 61.32014 & 43.61375 & 8.4 & 238 \\
\hline FDI & 71 & 3.627606 & 13.12158 & -16.06 & 103.93 \\
\hline Innovation Index & 71 & 42.67183 & 11.01136 & 23.3 & 67.2 \\
\hline MonetaryFreedom & 71 & 76.98873 & 11.4682 & 0 & 88 \\
\hline Governmenteff & 71 & 0.07 & 1.001144 & -2.02 & 1.94 \\
\hline
\end{tabular}

The first two variables are the binary dependent variables that will be analyzed to better address the determinants of hydrogen and CCS policies. "Policy type" is the categorial variable addressing whether the observed countries are investing in CCS, hydrogen, or both (in a cooperation between blue hydrogen and $\mathrm{CO}_{2}$ storage). Overall, the maximum and minimum values suggest that there are consistent differences within the countries. Fossil Fuel consumption is the first independent variable, and it is estimated in $\mathrm{KW} / \mathrm{h}$. The second variable represents the oil reserves for each country, including those reserves which can be potentially recovered. Debt/GDP ratio is the main indicator for the evaluation of the country's attitude towards hydrogen or CCS investment policies. Following Stavytskyy's approach [25], we have also included a trilemma index to indicate the total rating of the national energy system performance considering all three variables, i.e., energy security, energy equity and environmental sustainability. It represents the ability of a country to mitigate potential risks correlated to climate and environmental changes, including decarbonization strategies. Energy equity represents power access and basic-energy resource affordability, while energy security focuses on the reliability of the infrastructure and domestic/external energy resource balance. In the latest year, access to electricity and clean cooking have increased by $87 \%$ and $75 \%$, respectively, while the energy mix is shifting 
towards renewable energy sources, which have increased by $7 \%$ in 2020 , with a 200GW greater capacity in the production plants [32].

In 2019, Switzerland was the best-performing country, with an index of 84.3, followed by Sweden, with 84.2 , and Denmark, with 84 . The last one is a proxy for both eco-innovation and knowledge.

Foreign Direct Investments are intended to be the net inflow from foreign investors. The Monetary Freedom Index is a proxy for a government's stability, considering the weighted average inflation rate of the last three years and price controls. It varies from 0 to 100. The third one is government effectiveness as proxy for people's perceptions of a country's quality with regard to public services and independence from political pressure, including good standards for policy formulation and implementation. It ranges from -2.5 to 2.5 .

All of the variables are expressed as per capita values in order to avoid biased information due to the different magnitudes of countries' indices. The correlation matrix showed a high correlation between the Trilemma Index and the Innovation Index. For the purpose of this paper, the Trilemma Index will be considered as a proxy for sustainable activities and environmental innovation impact.

\subsection{Model Framework}

Considering the dichotomic and categorical variable of the dependent variables, both logit and probit-in their multinomial form for the categorical variable - were valid choices for this framework.

As explained by Hahn and Soyer [33], probit and logit models fit the data similarly well in small datasets, with the difference that the probit model assumes normal regression for the distribution of residuals. Even though the logit model is often preferred by researchers due to its easier interpretation of coefficients, we decided to proceed with probit and multinomial probit, considering that the difference in the two cumulative distributions is not so significative, but with the pros that the probit model allows us to relax the IIA intake in part, dividing the various alternatives into various similar subgroups, but independently from the others. The multinomial probit model completely relaxes the IIA assumption, allowing the residuals-in matrix form-to be correlated. For these reasons, we believe that probit estimation provides better and more consistent results.

Assuming $Y$ as the dependent binary variable, the probit model will be represented as:

$$
\begin{aligned}
& P\left(Y_{i}=0 \mid x_{1}, x_{2}, \ldots x_{7}\right)=\operatorname{Pr}\left(Y_{i}^{*} \leq 0\right)=\phi\left(x_{i}^{T} \beta\right) \\
& =1-\phi\left(\beta_{0}+\beta_{1} X_{\text {fossil fuel consumption }}+\beta_{2} X_{\text {oil reserves }}\right. \\
& +\beta_{3} X_{\text {Trilemma index }}+\beta_{4} X_{\text {DebtGDPRatio }} \\
& +\beta_{5} X_{\text {Foreign Direct Investments }}+\beta_{6} X_{\text {Monetary Freedom }} \\
& +\beta_{7} X_{\text {Government effectiveness }} \text { ) } \\
& P\left(Y_{i}=1 \mid x_{1}, x_{2}, \ldots x_{7}\right)=\operatorname{Pr}\left(Y_{i}^{*}>0\right)=\phi\left(x_{i}^{T} \beta\right) \\
& =\phi\left(\beta_{0}+\beta_{1} X_{\text {fossil fuel consumption }}+\beta_{2} X_{\text {oil reserves }}\right. \\
& +\beta_{3} X_{\text {Trilemma index }}+\beta_{4} X_{\text {DebtGDPRatio }} \\
& +\beta_{5} X_{\text {Foreign Direct Investments }}+\beta_{6} X_{\text {Monetary Freedom }} \\
& \left.+\beta_{7} X_{\text {Government effectiveness }}\right) \\
& \text { Model 1: } Y_{1_{i}}=\left\{\begin{array}{c}
0 \text { with no Hydrogen Policy } \\
1 \text { with Hydrogen Policy }
\end{array}\right. \\
& \text { Model 2: } Y_{2_{i}}=\left\{\begin{array}{c}
0 \text { with no CCS Policy } \\
1 \text { with CCS Policy }
\end{array}\right.
\end{aligned}
$$

where $\phi$ is the cumulative distribution function of standard normal distribution.

The first model will consider $Y$ as a dichotomous variable, assuming values of zero or one for the absence or presence of hydrogen policies in that country, respectively. 
The second one will replicate the model, considering the absence/presence of a CCS policy as the new dependent variable. The estimated curve will be an S-shaped cumulative normal distribution.

A third model will finally be computed in order to estimate the probit model on categorical variables, assuming a value of 0 for a CCS policy, 1 for an integrated CCS- $\mathrm{H}_{2}$ policy, 3 for a Green $\mathrm{H}_{2}$ policy, and 4 for an absence of those policies for each observed country.

$$
\text { Model 3: } Y_{3_{i}}=\left\{\begin{array}{c}
1 \text { with CCS policy } \\
2 \text { with CCS }+ \text { Blue H2 policy } \\
3 \text { with Green H2 policy } \\
4 \text { with no CCS / H2 policy }
\end{array}\right.
$$

Fit and diagnostic tests were carried out before running the model. Heteroscedasticity is a very common and often-discussed problem in models like probit models, simply because a dependent variable is a probability which will express uncertainties deriving from the omitted variable bias issue. In this case, we have corrected this issue with robust estimation in Stata.

\section{Results}

\subsection{Model Estimation}

Tables 4 and 5 show the results estimated from binary probit models through the maximum likelihood method.

Table 4. Binary probit model 1 results.

\begin{tabular}{ccccccc}
\hline \multicolumn{7}{c}{ Estimated Probit Model on Hydrogen Policy } \\
\hline Variable & Coefficient & Std. Err. & $\mathbf{z}$ & $\boldsymbol{p}>\mathbf{z}$ & [95\% Conf. & Interval] \\
\hline FossFuelCons & 0.0014202 & 0.0004119 & 3.45 & 0.001 & 0.0006128 & 0.0022275 \\
\hline Tril_Index & 0.210363 & 0.0633927 & 3.32 & 0.001 & 0.0861156 & 0.3346104 \\
\hline Oil_reserves & -0.0073881 & 0.0045246 & -1.63 & 0.102 & -0.016256 & 0.0014799 \\
\hline DebtGDPratio & 0.0191029 & 0.0061923 & 3.08 & 0.002 & 0.0069663 & 0.0312396 \\
\hline FDI & -0.0702348 & 0.0282648 & -2.48 & 0.013 & -0.1256328 & -0.0148368 \\
\hline MonetaryFreedomIndex & 0.0045349 & 0.0215461 & 0.21 & 0.833 & -0.0376947 & 0.0467644 \\
\hline Governmenteffectiveness & 0.2961982 & 0.2308718 & 1.28 & 0.200 & -0.1563023 & 0.7486987 \\
\hline _cons & -18.22392 & 4.918261 & -3.71 & 0.000 & -27.86354 & -8.584306 \\
\hline Log likelihood & -21.488297 & & & & & \\
\hline Wald chi2(7) & 21.26 & & & & \\
\hline Cragg\&Uhler R-sq & 0.687 & & & & \\
\hline Prob>chi2 & 0.0034 & & & & \\
\hline
\end{tabular}

The Wald Likelihood tests show that at least one of the predictors' regression coefficients is different from zero. Moreover, the p-value confirms the goodness of fit of the model rejecting the hypothesis that at least one of the coefficients in the models is equal to zero. Cragg and Uhler's R-squared for the models are 0.687 and 0.554 , respectively, highlighting that the models predict quite well the outcome of $\mathrm{H}_{2} / \mathrm{CCS}$ policy likelihood. Differently from OLS and similar models, the results show z-statistics as a ratio of coefficients with respect to standard errors. The P-values reflect the probability of $z$ test statistics under a null hypothesis that its coefficient is zero.

Coefficient interpretation for probit distribution is not straightforward. It is important to remember that for these kinds of models, a change in the coefficients depends both on their starting values and other variables. In general terms, an increase of $X$ leads to $B$ change in a z-score of $Y$. The constant terms are both statistically significant and not so different in their z-statistics. As expected, if all of the coefficients are zero, the predicted 
probability of a hydrogen or CCS policy seems to be extremely low. This underlines the fact that the variable chosen for the estimation might well explain —at least partially- the determinants affecting those policies. The results also show that the Debt/GDP ratio turned out to be statistically significant at the $10 \%$ level for the first model, given all of the other predictors in the model. This result has to be interpreted along with the negative statistically significant result at the $5 \%$ level for Foreign Direct investments: an increase in the debt/GDP ratio seems to lead to an increase of the predicted probability of a hydrogen policy, while an increase of foreign direct investments seems to lead to a decrease of the predicted probability.

Table 5. Binary probit model 2 results.

\begin{tabular}{ccccccc}
\hline \multicolumn{7}{c}{ Estimated Probit Model on CCS Policy } \\
\hline Variable & Coefficient & Std. Err. & $\mathbf{z}$ & $\boldsymbol{p}>\mathbf{z}$ & [95\% Conf. & Interval] \\
\hline FossFuelCons & 0.0012508 & 0.0003285 & 3.81 & 0.000 & 0.000607 & 0.0018947 \\
\hline Tril_Index & 0.1032483 & 0.0331886 & 3.11 & 0.002 & 0.0381999 & 0.1682968 \\
\hline Oil_reserves & 0.0102415 & 0.0053245 & 1.92 & 0.054 & -0.0001944 & 0.0206773 \\
\hline DebtGDPratio & 0.0055436 & 0.0035196 & 1.58 & 0.115 & -0.0013546 & 0.0124418 \\
\hline FDI & -0.0486122 & 0.0298179 & -1.63 & 0.103 & -0.1070542 & 0.0098298 \\
\hline MonetaryFreedomIndex & 0.0522676 & 0.020892 & 2.50 & 0.012 & 0.0113199 & 0.0932152 \\
\hline Governmenteffectiveness & -0.1631639 & 0.2069373 & -0.79 & 0.430 & -0.5687537 & 0.2424258 \\
\hline _cons & -13.37904 & 3.024641 & -4.42 & 0.000 & -19.30722 & -7.450849 \\
\hline Log likelihood & -26.780267 & & & & & \\
\hline Wald chi2 (7) & 29.97 & & & & & \\
\hline Cragg\&Uhler R-sq & 0.554 & & & & & \\
\hline Prob > chi2 & 0.0001 & & & & \\
\hline
\end{tabular}

Fossil fuel consumption and the trilemma index turned out to be statistically significant at the $1 \%$ level in both cases, given the other predictors in the model: this means that the likelihood of those independent variables seems to increase as the explanatory variables increase. As fossil fuel consumption and the trilemma index increase, the tendency to have in place CCS or hydrogen policies also increases in order to fulfill carbon-reduction policy goals.

The monetary freedom index is statistically significant at the $5 \%$ level for the second model, which means that an increase of price stability seems to be positively connected with the likelihood of a CCS investment policy.

In order to better address the coefficient interpretations, the relationship between specific variables and the probability outcome will be addressed through marginal effects. The results are shown in Tables 6 and 7.

Table 6. Marginal effects after probit (Model 1).

\begin{tabular}{ccccccc}
\hline dy/dx & Std. Err. & $\mathbf{z}$ & $\boldsymbol{p} \mathbf{z} \mathbf{z}$ & [95\% Conf. & \multicolumn{2}{c}{ Interval] } \\
\hline FossFuelCons & 0.0002381 & 0.0000561 & 4.24 & 0.000 & 0.0001282 & 0.0003481 \\
\hline Tril_Index & 0.0352753 & 0.0069206 & 5.10 & 0.000 & 0.0217113 & 0.0488394 \\
\hline Oil_reserves & -0.0012389 & 0.0007298 & -1.70 & 0.090 & -0.0026693 & 0.0001915 \\
\hline DebtGDPratio & 0.0032033 & 0.0008699 & 3.68 & 0.000 & 0.0014983 & 0.0049083 \\
\hline FDI & -0.0117775 & 0.0044253 & -2.66 & 0.008 & -0.0204509 & -0.0031041 \\
\hline MonetaryFreedomIndex & 0.0007604 & 0.0036112 & 0.21 & 0.833 & -0.0063173 & 0.0078382 \\
\hline Governmenteffectiveness & 0.0496688 & 0.0367136 & 1.35 & 0.176 & -0.0222886 & 0.1216262 \\
\hline
\end{tabular}


Table 7. Marginal effects after probit (Model 2).

\begin{tabular}{ccccccc}
\hline dy/dx & Std. Err. & $\mathbf{z}$ & $p>\mathbf{z}$ & [95\% Conf. & \multicolumn{2}{c}{ Interval] } \\
\hline FossFuelCons & 0.0002614 & 0.0000528 & 4.95 & 0.000 & 0.0001578 & 0.000365 \\
\hline Tril_Index & 0.0215779 & 0.0064657 & 3.34 & 0.001 & 0.0089055 & 0.0342504 \\
\hline Oil_reserves & 0.0021404 & 0.0010695 & 2.00 & 0.045 & 0.0000442 & 0.0042365 \\
\hline DebtGDPratio & 0.0011586 & 0.000708 & 1.64 & 0.102 & -0.0002291 & 0.0025462 \\
\hline FDI & -0.0101595 & 0.006076 & -1.67 & 0.095 & -0.0220682 & 0.0017492 \\
\hline MonetaryFreedomIndex & 0.0109234 & 0.0040645 & 2.69 & 0.007 & 0.0029572 & 0.0188897 \\
\hline Governmenteffectiveness & -0.0340997 & 0.0426602 & -0.80 & 0.424 & -0.1177121 & 0.0495127 \\
\hline
\end{tabular}

Here, we do not want to belabor the magnitude of marginal effects or the expected probability: we are more interested in the analysis of the determinants affecting green policies and how the variables interact with each other. Therefore, the signs of coefficients might give a more accurate interpretation of the overall effect, rather than the expected probability linked to small changes.

It seems that, overall, the interpretation given before was made pretty accurate by looking at the marginal effects. An increase in fossil fuel consumption slightly raises the probability outcome of a $\mathrm{H}_{2}$ or CCS policy. On the contrary, it seems that increasing oil reserves slightly decrease the probability outcome of a hydrogen policy. This indirectly explains the priority need to guarantee a certain energy autonomy, and that only its weakness can spur government authorities to search for and encourage new energy sources, which are obviously supplementary to the currently lacking ones.

The last model aims to further analyze the relationship between blue and green hydrogen through the categorical variable. Table 8 reports the results of the multinomial probit model, taking into consideration blue hydrogen combined with CCS projects as a base category.

Table 8. Multinomial probit model 3 results.

\begin{tabular}{|c|c|c|c|c|c|c|}
\hline Policy_Type. & Coefficient & Std. Err. & $\mathbf{z}$ & $p>\mathrm{z}$ & [95\% Conf. & Interval] \\
\hline \multicolumn{7}{|l|}{ CCS } \\
\hline FossFuelCons & -0.0020642 & 0.0008646 & -2.39 & 0.017 & -0.0037588 & -0.0003696 \\
\hline Oil_reserves & 0.0070005 & 0.0055228 & 1.27 & 0.205 & -0.0038239 & 0.0178249 \\
\hline Tril_Index & -0.47288 & 0.1382811 & -3.42 & 0.001 & -0.743906 & -0.201854 \\
\hline DebtGDPratio & -0.0248556 & 0.0111908 & -2.22 & 0.026 & -0.0467893 & -0.002922 \\
\hline FDI & -0.0026835 & 0.0597126 & -0.04 & 0.964 & -0.1197181 & 0.1143511 \\
\hline MonetaryFreedomIndex & 0.0151796 & 0.0287181 & 0.53 & 0.597 & -0.0411069 & 0.071466 \\
\hline Governmenteffectiveness & -0.818717 & 0.4942396 & -1.66 & 0.098 & -1.787409 & 0.1499749 \\
\hline _cons & 37.02672 & 11.19304 & 3.31 & 0.001 & 15.08877 & 58.96467 \\
\hline $\mathrm{CCS} \mathrm{H}_{2}$ & \multicolumn{6}{|c|}{ (base outcome) } \\
\hline \multicolumn{7}{|l|}{ Green_H ${ }_{2}$} \\
\hline FossFuelCons & -0.0010754 & 0.0006071 & -1.77 & 0.077 & -0.0022653 & 0.0001146 \\
\hline Oil_reserves & -0.5772029 & 0.2651788 & -2.18 & 0.030 & -1.096944 & -0.057462 \\
\hline Tril_Index & -0.277432 & 0.1063659 & -2.61 & 0.009 & -0.4859052 & -0.0689587 \\
\hline DebtGDPratio & -0.0078606 & 0.0074699 & -1.05 & 0.293 & -0.0225014 & 0.0067802 \\
\hline FDI & -0.0211665 & 0.0644133 & -0.33 & 0.742 & -0.1474143 & 0.1050813 \\
\hline MonetaryFreedomIndex & -0.1012519 & 0.058649 & -1.73 & 0.084 & -0.2162017 & 0.0136979 \\
\hline Governmenteffectiveness & 0.16988 & 0.415198 & 0.41 & 0.682 & -0.6438931 & 0.9836531 \\
\hline _cons & 31.09923 & 8.411704 & 3.70 & 0.000 & 14.61259 & 47.58586 \\
\hline None & & & & & & \\
\hline
\end{tabular}


Table 8. Cont.

\begin{tabular}{ccccccc}
\hline Policy_Type. & Coefficient & Std. Err. & $\mathbf{z}$ & $\boldsymbol{p}>\mathbf{z}$ & {$[95 \%$ Conf. } & Interval] \\
\hline FossFuelCons & -0.0033817 & 0.0008494 & -3.98 & 0.000 & -0.0050464 & -0.0017169 \\
\hline Oil_reserves & -0.0020461 & 0.007836 & -0.26 & 0.794 & -0.0174044 & 0.0133122 \\
\hline Tril_Index & -0.5088215 & 0.1431639 & -3.55 & 0.000 & -0.7894176 & -0.2282253 \\
\hline DebtGDPratio & -0.0323601 & 0.0122361 & -2.64 & 0.008 & -0.0563425 & -0.0083778 \\
\hline FDI & 0.0942413 & 0.0587688 & 1.60 & 0.109 & -0.0209434 & 0.2094259 \\
\hline MonetaryFreedomIndex & -0.0497465 & 0.0354158 & -1.40 & 0.160 & -0.1191602 & 0.0196672 \\
\hline Governmenteffectiveness & -0.2321935 & 0.4533384 & -0.51 & 0.609 & -1.12072 & 0.6563334 \\
\hline _cons & 47.20772 & 11.82132 & 3.99 & 0.000 & 24.03836 & 70.37708 \\
\hline
\end{tabular}

Table 9 will better address this topic by examining the marginal effects of the model, taking into consideration explanatory "CCS-Blue $\mathrm{H}_{2}$ " as a base category variable.

Table 9. Marginal effects after the multinomial probability model.

\begin{tabular}{cccccccc}
\hline Variable & $\mathbf{d y} / \mathbf{d x}$ & Std. Err. & $\mathbf{z}$ & $p>\mathbf{z}$ & {$[\mathbf{9 5 \%}$} & C.I.] & $\mathbf{X}$ \\
\hline FossFuel & 0.0008132 & 0.00027 & 3.04 & 0.002 & 0.000288 & 0.001338 & 1457.96 \\
\hline Oil_reserves & -0.0004322 & 0.00179 & -0.24 & 0.809 & -0.003933 & 0.003069 & 19.5006 \\
\hline Tril_Ind & 0.1405383 & 0.04016 & 3.50 & 0.000 & 0.061823 & 0.219254 & 71.9141 \\
\hline DebtGDP & 0.0083533 & 0.0033 & 2.54 & 0.011 & 0.001895 & 0.014812 & 61.3201 \\
\hline FDI & -0.015917 & 0.01508 & -1.06 & 0.291 & -0.045464 & 0.01363 & 3.62761 \\
\hline Monetary & 0.0068601 & 0.00866 & 0.79 & 0.428 & -0.010114 & 0.023834 & 76.9887 \\
\hline Government & 0.1316791 & 0.12391 & 1.06 & 0.288 & -0.111172 & 0.37453 & 0.07 \\
\hline
\end{tabular}

The last category of the model clearly shows the determinants affecting investment in blue hydrogen policies for a general country. By looking at the marginal effects, when fossil fuel consumption increases by one unit-intended as one thousand KWh-the blue hydrogen-CCS option's probability slightly increases. The trilemma index, which is statistically negatively significant at the $5 \%$ level for both CCS and Green $\mathrm{H}_{2}$ policies over a Blue-CCS one, can be interpreted as the likelihood of preferring a blue hydrogen policy over a CCS and-more importantly-a green one. Looking at the results for the "CCS" and "None" categories, fossil fuel consumption seems to directly affect blue and green hydrogen policies, rather than CCS-only ones. The Debt/GDP ratio is statistically negatively significant in the first "CCS", and it has a positive sign in the marginal effect results, which outlines a mild preference on a combined blue hydrogen policy over CCS ones. Its coefficient in "None" category outlines that the Debt/GDP ratio seems to trigger investment decisions, and again confirms our first hypothesis of the importance of public debt for this kind of policy. The foreign direct investment coefficient is not statistically significant in this model, just like monetary freedom and government effectiveness. On the contrary, while oil reserves were not statistically significant in Models 1 and 2, here an increase of one billion barrels of oil reserves would slightly decrease the likelihood for a blue $\mathrm{H}_{2}$-CCS policy, and also for a green one, as denoted by the results of the third category. This means that oil reserves negatively affect both hydrogen policies, and they have to be interpreted differently from fossil fuel consumption.

\subsection{Discussion}

Overall, the results of the analyzed models match with the data mentioned before: most of the countries investing in hydrogen are indeed "wealthy" countries that have not suffered much from European austerity, or are international rich countries. Countries lack hydrogen or CCS policies because they do not have enough financing to do so, or they are too linked to oil reserves [34,35]. In fact, crossing the indications of the results outlined 
above, it emerges that the priority expansion of investments in the development sectors of the hydrogen industrial chain tend to be more likely to occur where there are no substantial public budget constraints, in the sense that the degrees of public spending freedoms are greater and more likely to expand, and where a relatively low level of oil reserves is observed. This means that the policies to stimulate the hydrogen industry are to be linked to the priority security needs of energy supplies in economically strong countries, and where such security - which becomes "energy autonomy"-becomes a crucial feature for the policy maker [36].

While fossil fuel consumption is related to emissions, which require solutions to reach the zero-carbon emission target worldwide, oil reserves are strictly correlated to large oil countries' producers and owners, and are less correlated to emissions in the same way as fossil fuel consumption. This underlines the fact that there is a huge portion of countries with large oil reserves which are not currently investing in hydrogen policies, such as Egypt, Hungary, Kuwait, Russia and others. Oil and gas activities still play a major role in the worldwide economy, and we are very far from assessing a global sustainable strategy [37]. Countries still depend on oil and gas to create and supply power demand at both the national and international levels. Due to the difficulties and economic risks of hydrogen investments, they would not choose to invest in those technologies, unless external factors occurred.

Almost all Member States have included green or blue hydrogen plans in their national energy and climate plans, and have joined the "Hydrogen Initiative". In total, 14 Member States have also included hydrogen in the context of their national policy frameworks for alternative fuel infrastructure [38].

Although green hydrogen is certainly the favorite in a long-term decarbonization policy, nowadays it is very difficult to invest in this technology due to the high production costs. In order to comply with the Green New Deal and the Paris Agreement, countries rather decided to start with investments in blue hydrogen.

Sustainability must also be economic sustainability, and investments must also be sustainable in the long term [39]. Today, hydrogen can only be "blue", both for economic and financial reasons, and for reasons of the available reserves and prospects of the technological improvement of CCS. The EU is particularly focusing on blue hydrogen because it is cheaper [11]. However, this strategy could prove to be a failure. Natural gas production currently produces excess methane, which is burned off as a means of disposal. Some authors $[40,41]$ argue that the greenhouse gas emissions from the production of blue hydrogen may be greater than those from fossil fuels. The best idea would be to capture and convert the gas, reducing more emissions in the near-term.

What matters most is that investing in hydrogen requires huge public investments. This is confirmed by the result that foreign direct investments seem to mitigate investment in that sector, meaning that most of the financing must come from the local/national level, and cannot be sourced from outsider international investors [42]. Moreover, countries with a good debt/GDP ratio in the first place were able to invest in hydrogen infrastructure and plants, while those with excessive and heavy public debt were left out from the equation [43].

Government effectiveness did not turn out to be statistically significant in any of the models. The perception from citizens on the degree of independence from political pressure and the credibility of the government's commitment to policies seems not to be a triggering factor for hydrogen. This is explained both by the difficulty of capturing the phenomenon of governments' effectiveness with respect to incentive strategies for the development of the hydrogen supply chain, and by the priority will and need to aim, in any case, at overcoming direct public intervention.

The results confirmed those of Stavystsky [25] in that energy security-in our case in a broadened consideration of energy efficiency-does affect investments in hydrogen. The last model showed that higher energy efficiency and the possibility to raise debt to finance projects will more likely lead to a blue hydrogen policy. 
Additionally, the results discovered by Safarzyńska et al. [18], regarding renewables in general terms, are also applicable to hydrogen investments. Greater price stability does have an impact on investment in hydrogen, especially for fossil-fuel-consuming countries, due to the high risk of those investments' projects.

\section{Conclusions}

In this paper, we analyzed the relationship between the applied hydrogen strategies at the national level and, specifically green and blue hydrogen and CCS, through some key variables which help to explain the differences between hypothetical blue or green hydrogen strategies. This type of analysis appears to be decidedly innovative in the reference literature. After a brief introduction of the topic, including an estimation of the actual prices for green and blue hydrogen, the analysis focused on fossil-fuel-dependent countries and public investment trends. Through a probit estimation on 71 countries, considering the data of 2019, we estimated the likelihood of having a green hydrogen policy rather than a blue/CCS one. The major takeovers of the analysis are summarized as follow.

First of all, national public debt plays a major role in national hydrogen policy investment decisions; as such, the priority expansion of investments in the development sectors of the hydrogen industrial chain tends to be more likely to occur where there are no substantial public budget constraints, in the sense that the degrees of public spending freedoms are greater and more likely to expand.

Secondly, the Monetary Freedom Index, as a proxy for a governments' stability, proved to be significant due to the fact that, according our results, an increase of price stability is positively connected with the likelihood of a CCS investment strategy, which is obviously locally based, meaning that most of the financing must come from the local/national level and cannot be sourced from outsider international investors. Specifically, an increase in the debt/GDP ratio seems to lead to an increase of the predicted probability of a hydrogen policy, while an increase of foreign direct investments seems to lead to a decrease of the predicted probability. Indeed, countries with a good debt/GDP ratio in first place were able to invest in hydrogen infrastructure and plants. In particular, then, it was observed that energy-efficient countries with an efficient Public Debt/GDP ratio are currently investing in (blue) hydrogen. Because we consider current projects, both active and in progress, this shows that energy efficient countries are now more likely willing to invest in blue hydrogen rather than green hydrogen. This result confirms and is aligned with EU hydrogen strategy 2020 and the New Green Deal.

Another important conclusion comes from the result that countries which are strictly dependent on oil might not be willing to invest in national hydrogen political strategies. This conclusion is reinforced by the further result according to which it seems that increasing national oil reserves slightly decrease the probability outcome of a hydrogen policy. On the contrary, as the fossil fuel consumption with our significant national oil reserves and nationally specified trilemma index increases, the tendency to have in place CCS or hydrogen policies increases as well to fulfill carbon-reduction policy goals or, for greater precision, slightly raises the probability outcome of an $\mathrm{H}_{2}$ or CCS policy. Such results indirectly explain the priority need to guarantee a certain energy autonomy, and that only its weakness can spur government authorities to search for and encourage new energy sources, which are obviously supplementary to the currently lacking ones. The greater cost-effectiveness and the sudden availability of blue hydrogen contributed to reinforce the result of our empirical analysis according to which if fossil fuel consumption increases by one unit-intended as one thousand KWh-the blue hydrogen-CCS option's probability slightly increases.

We believe that the conclusion that can be drawn from the set of results given so far is important: the expansion of investments in the sectors of the hydrogen industrial chain tends to be more likely to occur not only where there are no substantial public budget constraints and where we observe a good governments' stability but also where 
a relatively low level of oil reserves is observed (because oil reserves negatively affect both blue and green hydrogen policies). This means that the policies to stimulate the hydrogen industry are to be linked to the priority security needs of energy supplies in economically strong countries, and where such security-which becomes "energy autonomy" - becomes a crucial feature for the policy maker.

Further research should focus on the evaluation of the actual and perspective costefficient reductions and should evaluate a more precise pricing for green and blue hydrogen, as well as the effective carbon reduction of those two technologies.

Author Contributions: Writing—original draft, F.P.; Writing—review and editing, R.F. All authors have read and agreed to the published version of the manuscript.

Funding: This research received no external funding.

Institutional Review Board Statement: Not applicable.

Informed Consent Statement: Not applicable.

Data Availability Statement: The data used in this paper can be found in: [Dataset] Global economy, world economy. (n.d.)—https:/ / www.theglobaleconomy.com/ (accessed on 1 May 2021); [Dataset] IEA (2020), Hydrogen Projects Database, IEA, Paris-https: / /www.iea.org/reports/the-future-ofhydrogen (accessed on 1 May 2021).

Conflicts of Interest: The authors certify that they have NO affiliations with or involvement in any organization or entity with any financial interest (such as honoraria; educational grants; participation in speakers' bureaus; membership, employment, consultancies, stock ownership, or other equity interest; or expert testimony or patent-licensing arrangements) or non-financial interest (such as personal or professional relationships, affiliations, knowledge or beliefs) in the subject matter or materials discussed in this manuscript.

\section{References}

1. Chun, D.; Hong, S.; Chung, Y.; Woo, C.; Seo, H. Influencing factors on hydrogen energy R\&D projects: An ex-post performance evaluation. Renew. Sustain. Energy Rev. 2016, 53, 1252-1258. [CrossRef]

2. Ding, H.; Zhou, D.; Zhou, P. Optimal policy supports for renewable energy technology development: A dynamic programming model. Energy Econ. 2020, 92, 104765. [CrossRef]

3. Ding, H.; Su, B.; Zhou, D.; Wang, Q. Literature Review on Renewable Energy Development and China's Roadmap. Front Eng. Manag. 2021, 8, 212-222.

4. International Renewable Energy Agency. Renewable Energy Policies in a Time of Transition; International Renewable Energy Agency: New York, NY, USA, 2018; pp. 1-112. ISBN 978-92-9260-061-7.

5. Kelly, G. Renewable energy strategies in England, Australia and New Zealand. Geoforum 2006, 38, 326-338. [CrossRef]

6. National Energy Regulator South Africa (NERSA). Rules on Selection Criteria for Renewable Energy Projects under the REFIT Programme; National Energy Regulator South Africa (NERSA): Arcadia, Pretoria, 2009.

7. Viklund, M. Energy policy options-From the perspective of public attitudes and risk perceptions. Energy Policy 2004, 32, 1159-1171. [CrossRef]

8. Salim, R.A.; Rafiq, S. Why do some emerging economies proactively accelerate the adoption of renewable energy? Energy Econ. 2012, 34, 1051-1057. [CrossRef]

9. European Commission. Communication from the Commission to the European Parliament, the Council, the European Economic and Social Committee and the Committee of the Regions: A hydrogen strategy for a climate-neutral Europe; Global CCS Institute: Global Status of CCS 2020; European Commission: Brussels, Belgium, 2020.

10. Dumas, M.; Rising, J.; Urpelainen, J. Political competition and renewable energy transitions over long time horizons: A dynamic approach. Ecol. Econ. 2016, 124, 175-184. [CrossRef]

11. Biresselioglu, M.E.; Karaibrahimoglu, Y.Z. The government orientation and use of renewable energy: Case of Europe. Renew. Energy 2012, 47, 29-37. [CrossRef]

12. Abe, J.O.; Popoola, A.P.I.; Ajenifuja, E.; Popoola, O.M. Hydrogen energy, economy and storage: Review and recommendation. Int. J. Hydrog. Energy 2019, 44, 15072-15086. [CrossRef]

13. Chapman, A.; Itaoka, K.; Hirose, K.; Davidson, F.T.; Nagasawa, K.; Lloyd, A.C.; Webber, M.E.; Kurban, Z.; Managi, S.; Tamaki, T.; et al. A review of four case studies assessing the potential for hydrogen penetration of the future energy system. Int. J. Hydrog. Energy 2019, 44, 6371-6382. [CrossRef]

14. Global CCS Institute. Global Status of CCS 2020, November Report; Global Carbon Capture and Storage Institute: Melbourne, Australia, 2021. 
15. Dawood, F.; Anda, M.; Shafiullah, G. Hydrogen production for energy: An overview. Int. J. Hydrog. Energy 2020, 45, 3847-3869. [CrossRef]

16. IEA. Hydrogen Projects Database; IEA: Paris, France, 2020; Available online: https://www.iea.org/reports/hydrogen-projectsdatabase (accessed on 1 May 2021).

17. Noailly, J.; Smeets, R. Financing Energy Innovation: Internal Finance and the Direction of Technical Change. Environ. Resour. Econ. 2021, 1-25. [CrossRef]

18. Safarzyńska, K.; Bergh, J.C.V.D. Financial stability at risk due to investing rapidly in renewable energy. Energy Policy 2017, 108, 12-20. [CrossRef]

19. Wietschel, M.; Jokisch, S.; Boeters, S.; Schade, W.; Seydel, P. Macroeconomic impacts of hydrogen. In The Hydrogen Economy: Opportunities and Challenges; Ball, M., Wietschel, M., Eds.; Cambridge University Press: Cambridge, UK, 2010 ; pp. 529-562.

20. Tseng, P.; Lee, J.; Friley, P. A hydrogen economy: Opportunities and challenges. Energy 2005, 30, 2703-2720. [CrossRef]

21. Hart, P.; Freund, P.; Smith, A. Using Hydrogen-Today and Tomorrow; IEA Greenhouse Gas R\&D Programme: Cheltenham, UK, 1999.

22. Saba, S.M.; Müller, M.; Robinius, M.; Stolten, D. The investment costs of electrolysis-A comparison of cost studies from the past 30 years. Int. J. Hydrog. Energy 2018, 43, 1209-1223. [CrossRef]

23. Kawakami, Y.; Matsuo, Y.; Kako, M.; Hachiuma, T.; Yanagisawa, A. The Economic Impact of the Introduction of Hydrogen into Japan's Energy Systems towards 2050; Institute of Energy Economics: Tokio, Japan, 2013.

24. Lee, S.-H. The Impact of the Introduction of Hydrogen Energy into the Power Sector on the Economy and Energy. J. Korea Acad. Ind. Coop. Soc. 2016, 17, 502-507. [CrossRef]

25. Stavytskyy, A.; Kharlamova, G.; Giedraitis, V.; Šumskis, V. Estimating the interrelation between energy security and macroeconomic factors in European countries. J. Int. Stud. 2018, 11, 217-238. [CrossRef]

26. US Department of Energy (DOE); National Hydrogen Energy Roadmap. Toward a More Secure and Cleaner Energy Future for America. In Proceedings of the Results of the National Hydrogen Energy Roadmap Workshop, Washington, DC, USA, 2-3 April 2002.

27. Dunn, S. Hydrogen Futures: Toward a Sustainable Energy System (Worldwatch Institute, 2001); Reviewed 2012 by Dunn S. in Syracuse Science \& Technology Law Reporter; Springer: Berlin/Heidelberg, Germany, 2012; Volume 26.

28. Muthmann, D. European Hydrogen Backbone; Guidehouse: Chicago, IL, USA, 2020.

29. Nicolli, F.; Vona, F. Heterogeneous policies, heterogeneous technologies: The case of renewable energy. Energy Econ. 2016, 56, 190-204. [CrossRef]

30. [dataset] Global Economy, World Economy. 2021. Available online: https:/ /www.theglobaleconomy.com/ (accessed on 1 May 2021).

31. Antunes, M.; Viegas, M.; Varum, C.; Pinho, C. The Impact of Structural Funds on Regional Growth: A Panel Data Spatial Analysis. Intereconomics 2020, 55, 312-319. [CrossRef]

32. Greenreport. Energia, World Trilemma Index: Italia 16esima per Sicurezza, Equità e Sostenibilità. Economia Ecologica, Energia, Inquintamenti. 2018. Available online: https://greenreport.it/news/energia/energia-world-trilemma-index-italia-16esimaper-sicurezza-equita-e-sostenibilita / (accessed on 1 May 2021).

33. Hahn, E.D.; Soyer, R. Probit and Logit Models: Differences in the Multivariate Realm. J. R. Stat. Soc. Ser. B 2005, 1-12. Available online: http:/ / home.gwu.edu/ \{\}soyer/mv1h.pdf (accessed on 1 May 2021).

34. Finon, D.; Perez, Y. The social efficiency of instruments of promotion of renewable energies: A transaction-cost perspective. Ecol. Econ. 2007, 62, 77-92. [CrossRef]

35. Finon, D.; Lamy, M.; Menanteau, P. Prices versus Quantities: Environmental Policies for Promoting the Development of Renewable Energy; Institut d'Economie et de Politique de l'Energie: Paris, France, 2001.

36. Gummer, J.H.; Head, C.R. Hydrogen, hydropower and world poverty. Int. J. Hydropower Dams 2003, 5, 67-71.

37. Özesmi, U.; Özesmi, S.L. Ecological models based on people's knowledge: A multi-step fuzzy cognitive mapping approach. Ecol. Model. 2004, 176, 43-64. [CrossRef]

38. Lægreid, O.M.; Povitkina, M. Do Political Institutions Moderate the GDP-CO 2 Relationship? Ecol. Econ. 2018, 145, 441-450. [CrossRef]

39. Cadoret, I.; Padovano, F. The political drivers of renewable energies policies. Energy Econ. 2016, 56, 261-269. [CrossRef]

40. Howarth, R.W.; Jacobson, M.Z. How green is blue hydrogen? Energy Sci. Eng. 2021, 9, 1676-1687. [CrossRef]

41. Solomon, B.D.; Banerjee, A. A global survey of hydrogen energy research, development and policy. Energy Policy 2006, 34, 781-792. [CrossRef]

42. Böhringer, C. The synthesis of bottom-up and top-down in energy policy modeling. Energy Econ. 1998, 20, 233-248. [CrossRef]

43. Yang, X.; Heidug, W.; Cooke, D. An adaptive policy-based framework for China's Carbon Capture and Storage development. Front. Eng. Manag. 2019, 6, 78-86. [CrossRef] 